\title{
Avoiding pitfalls in overseas medical educational experiences
}

\author{
Kristen L Sessions ${ }^{a}$, J Dwight Phillips ${ }^{b}$, Stephen P Merry ${ }^{c}$ \\ ${ }^{a}$ MSIV, School of Medicine, Mayo Clinic, Rochester, MN, USA \\ ${ }^{b}$ MD, Professor, Department of Pediatrics and Adolescent Medicine, Mayo Clinic, Rochester, MN, USA \\ ${ }^{c} \mathrm{MD}, \mathrm{MPH}$, Assistant Professor, Department of Family Medicine, College of Medicine, Mayo Clinic, USA
}

\begin{abstract}
In the United States, there are a growing number of medical students participating in international health electives. These experiences have the potential to be mutually beneficial to both the host country and the student. However, there is a significant risk of unethical and damaging practices during these trips, including concerns for sending trainees without appropriate pre-travel preparation with inadequate accountability to local health care providers at a stage in their education that imposes an undue burden on the local health facilities. This article describes one first year medical student's experience in navigating common challenges faced in international health electives and offers practical advice enlightened by the literature on how to overcome them. We emphasize the need for students to ensure adequate pre-trip preparation, communicate their level of training clearly, practice cultural humility, ensure personal safety, and engage in projects needed by the host community.
\end{abstract}

\section{Background}

In the United States, American medical students are increasingly participating in international health electives in low and middle income countries (LMIC). One study reported that $63 \%$ of U.S. students entering medical school expressed a desire to participate in international rotations, and over one-third of graduating medical students had completed at least one international health elective. ${ }^{1}$ This growing interest to serve the poor within medical training aligns with the Christian call to ministry and service, both domestically and globally. However, with growing interest also brings about an increased concern for ethical practices in global health training and common pitfalls of "voluntourism". 2
Increased interest in global health has significant potential benefits for both host countries, and participating individuals and institutions. Medical students who participate in an international rotation are more likely to work in a resource-poor setting, care for poor and ethnic minorities, and choose primary care specialties after graduating., ${ }^{3,4}$ These experiences allow students to learn about culture and health in unique ways, improve their diagnostic skills, see a wide variety of new pathology, work in limited resource settings, and practice caring for diverse patient populations. ${ }^{5-8}$ The host communities and health systems benefit from the increased access to health care, health system strengthening by partnering with hospitals and schools in higher-income countries, and the improved quality of care through the academic rigor resulting from the medical students' curiosity or 
research projects they perform. One study noted that LMIC patients receiving care looked favorably on medical student involvement on health teams. ${ }^{9}$

Despite these benefits, there is real risk of disempowering, demeaning, dangerous, and unethical practices by medical trainees that can harm the very communities they are trying to serve. $^{2,10-14}$ These electives can be self-serving, doing little to strengthen or build sustainable health systems and imposing undue burden on the local health facilities, particularly if trainees are sent without appropriate training or accountability. ${ }^{14}$ Such electives can "undermine existing health care and cause great harm."15 Research efforts can be specifically concerning if proper measures are not taken to ensure culturally appropriate informed consent and consistently followed ethical guidelines to protect vulnerable populations. ${ }^{11}$ Global volunteerism, in general, has been criticized for being relief rather than development focused, ineffective, and often detrimental to host communities when poorly conceived and executed, and medical student LMIC electives often bear many resemblances to these widely criticized efforts. ${ }^{16}$

There is a growing body of literature on best practice guidelines, curriculum development, and ethical frameworks for short-term medical experiences in global health. ${ }^{3,5,7,14,17-21}$ Recommendations for medical students embarking on international electives include recognizing that the primary purpose of the trip is medical education, communicating level of training clearly to all parties, practicing cultural humility, ensuring personal safety, and focusing on activities relevant to and needed by the host. This article serves to offer practical advice aimed at medical students participating in international rotations in order to make trips maximally beneficial to both students and their host communities. It explores the learning of a first-year medical student trainee doing clinical rotations in Uganda, presenting experiences which were tested against the existing recommendations from the literature.

\section{Practical Lessons}

\section{Be a learner and communicate your level of training clearly}

At 24, the medical student standing next to me on rounds was my same age yet four years above me in training. She was a year short of having an M.D. and I was only half way through my basic science training. Due to the different structures of medical training in Uganda and the U.S., I was woefully under-qualified for my age and with that came a clear need for me to repeatedly explain my level of training and capabilities. More than once, I was asked about differential diagnoses or recommendations for treatment, tasks entirely appropriate for the fourth year Ugandan medical student but a mystery for my first-year self. There were many occasions where I was faced with admitting my own lack of knowledge or staying quiet and undertaking tasks above my level of training.

Medical students, particularly those in their pre-clinical years, may simply and appropriately be learners. ${ }^{22}$ Short-term experiences for medical students and residents are meant to expose students to new diseases, patient populations, and resource limitations as a foundation for their careers. However, while medical students are there to learn and expand their skills, students must be aware of their current skill level and limitations and communicate their level of training to the host staff and ensure supervision is comparable to the oversight they would receive in the U.S. ${ }^{15,22}$ On providing a clear understanding of a student's level of training to the host staff, students can begin to find ways to contribute to the team. For example, pre-clinical year medical students may assist with taking vitals, writing notes, as well as many other non-clinical responsibilities. More experienced trainees will be able to additionally contribute to patient care and perform more procedures but should continually seek the expertise of host site physicians and other health care providers. This practice ensures patients' safety as well as protecting the trainee from situations they are not 
equipped to handle. It also relieves team stress by establishing clear understanding of roles and responsibilities and provides opportunities for appropriate teaching. Simple clarification early on can save time, energy, and inappropriate task assignments which may otherwise be given throughout the rotation.

\section{Practice cultural humility}

Bwindi Community Hospital (BCH) was founded to provide care for the indigenous Batwa people after they were forced to leave their huntergatherer lifestyle in 1992. The majority of the community BCH serves lives on less than $\$ 2$ a day. While the physicians and staff speak English, the patients speak Rukiga, a local language. In one short month, I would not be able to fully appreciate the complexities, history, and culture of the community in which I was working. However, the staff, community members, and patients were all eager to teach when I was eager to learn. For a short stay, "cultural humility" became more important, and obtainable, than "cultural competency."

While information about the culture, politics, and history of a community are important pre-travel reading, a student cannot achieve "cultural competency" prior to arrival (implying that a foreign medical student could not be well-versed in the culture, beliefs, language, and nuances of a host community through simply reading about them). Even for expatriates who have spent significant time in a new community, full "competency" may never be obtainable. Instead, the focus should be shifted toward practicing cultural humility. Immersion in local activities can help build cultural understanding. Volunteers at all levels should continually seek to respect and learn about the culture in which they are living, understanding their own lack of knowledge while desiring insight into the lives of the people with whom they are working. Cultural humility means leaving judgments and superiority behind, and approaching each person with genuine respect and curiosity. Wear refers to this idea as "insurgent multiculturalism" challenging students to "ask tough questions about the roots of inequality and racism" and "examine power structures." 15,23 Trainees should be careful what they say about their local hosts and colleagues on social media; some, in expressing their initial reactions to new situations, have inadvertently insulted their hosts on globally visible internet sites.

While trainees may not have a complete understanding of the community they are serving, several skills can be universally applied and should be incorporated into pre-trip preparation. For example, learning appropriate use of a translator and skills in non-verbal communication may be more effective during pre-trip preparation than learning phrases in the local language. Situational simulations and case-based ethics trainings can also help to prepare students for diverse settings despite limited understanding of that culture. ${ }^{24,25}$

\section{Ensure personal safety}

Despite recommendations from his mentor back home, Chris* chose not to take HIV medications with him to Uganda. The likelihood of a needle stick seemed remote, and he felt confident, despite limited knowledge of the hospital, that he would have access to medications should he need them. While in Uganda, he quickly discovered that "bota-botas," or small motorcycles, were the primary form of transportation, and even on the unpaved roads with no helmet, he found he used them regularly. While each trip was short, over his seven months in Uganda, Chris took countless unhelmeted rides and worked with almost a hundred HIV positive patients. *name changed

Reports have shown that students take risks abroad they would not take at home. ${ }^{7,26}$ Novelty and excitement, compounded with a sense of limited options, can make safety a low priority for trainees abroad. Risks occur inside and outside the hospital. Medical risks include needle sticks, respiratory disease exposure, and lack of timely access to medical care. Outside the hospital, unsafe transportation and unfamiliar areas can put trainees 
at risk. For example, in Uganda, bota-botas are the primary, and often only available, mode of transportation. While riding on the back of a motorcycle without a helmet would be out of the question for many students in the U.S., in Uganda it can easily because a regular occurrence. One ride may seem "normal" or individually benign but continued indiscretion can result in substantial cumulative risk to a trainee over the course of a rotation. This risk can be avoided by good pretravel planning. Each participant should have a pretravel medicine consultation that includes transportation and body fluid safety discussions in addition to the usual topics of malaria prevention, immunization, and diarrhea self-management. HIV post-exposure prophylaxis should be provided to all trainees who will be engaged in direct patient care with a discussion about universal precautions. The Global Ambassadors for Patient Safety is an online training to help students effectively plan global health trips. ${ }^{27}$ Resources such as these can help trainees think through potential safety concerns for themselves and their patients before departing. ${ }^{28}$

\section{Ensure projects are relevant to and needed by the host}

Our team spent two months establishing baseline research about HIV before departure with the aim to work with the HIV clinic at $\mathrm{BCH}$. When we arrived, however, staff had changed, and it became evident that most volunteers worked in HIV or maternal health. This area was well covered but their newly established mental health clinic was "less attractive" to donors and volunteers alike. While they were happy to have help in all areas of research, community understanding of mental health was poorly explored and significantly more needed than the list of proposed projects we had developed. It became evident they were going along with our wishes. After further discussion, we realized that a mental health services quality improvement project would be more beneficial to the hospital than our original plans. Listening to them allowed us to contribute in significantly more meaningful ways.

Quality improvement projects can provide much needed services to a hospital or health system. Medical students should look for ways to engage in activities most needed by the community they are serving. Trainees pre-planning with an open mind and actively searching for under-studied topics within health systems can contribute in meaningful ways, even on short term trips.

Research and quality improvement projects can raise significant ethical concerns and result in significant unforeseen costs. The costs for printing or translation services, and other community or staff involvement, may further stress already overworked human resources and should be carefully considered and counted when designing a project. Global health ethics training using case studies can help students work through how they would handle ethical conflicts before they are in-country. While programs sending students to other countries should have clear protocols for student engagement, it is ultimately the student's responsibility to ensure that project methods and topics are respectful, ethical, and beneficial to the hospital.

\section{Conclusion}

Informed by globalization and compelled by altruism and an ethic of social justice, more medical students and residents are traveling abroad each year on international health electives, thus helping to meet the need for culturally-sensitive and globally-educated physicians. While wellintentioned and potentially beneficial, critics have appropriately raised multiple concerns about the self-serving and potentially harmful nature of their involvement. However, training and pre-travel preparation by students can help make these trips mutually beneficial. Trainees should approach trips with honesty about their skill sets, practice cultural humility, and seek to design relevant and needed quality improvement or research projects requested by their hosts. In this way, students can feel comfortable in their role as a learner while finding 
meaningful ways to contribute to the host health care team.

\section{References}

1. Matriculating Student Questionnaire: All Schools Summary Report. Washington, DC: Association of American Medical Colleges; 2010.

2. McLennan S. Medical voluntourism in Honduras: 'Helping' the poor? Prog Develop Stud. 2014;14(2):163-79. http://dx.doi.org/10.1177/1464993413517789

3. Crump JA, Sugarman J. Ethical considerations for short-term experiences by trainees in global health. JAMA. 2008;300(12):1456-8. http://dx.doi.org/10.1001/jama.300.12.1456

4. Ramsey AH, Haq C, Gjerde CL, Rothenberg D. Career influence of an international health experience during medical school. Fam Med. 2004;36(6):412-6.

5. Crump JA, Sugarman J. Working Group on Ethics Guidelines for Global Health T. Ethics and best practice guidelines for training experiences in global health. Am J Trop Med Hyg. 2010;83(6):1178-82. http://dx.doi.org/10.4269/ajtmh.2010.10-0527

6. Thompson MJ, Huntington MK, Hunt DD, Pinsky LE, Brodie JJ. Educational effects of international health electives on U.S. and Canadian medical students and residents: a literature review. Acad Med.

2003;78(3):342-7.

http://dx.doi.org/10.1097/00001888-200303000$\underline{00023}$

7. Wilson JW, Merry SP, Franz WB. Rules of engagement: the principles of underserved global health volunteerism. Am J Med. 2012;125(6):612-7. http://dx.doi.org/10.1016/j.amjmed.2012.01.008

8. Sawatsky AP, Rosenman DJ, Merry SP, McDonald FS. Eight years of the Mayo International Health Program: what an international elective adds to resident education. Mayo Clin Proc. 2010;85(8):73441. http://dx.doi.org/10.4065/mcp.2010.0107

9. DeCamp M, Enumah S, O'Neill D, Sugarman J. Perceptions of a short-term medical programme in the Dominican Republic: voices of care recipients. Glob Public Health. 2014;9(4):411-25. http://dx.doi.org/10.1080/17441692.2014.893368

10. Martiniuk AL, Manouchehrian M, Negin JA, Zwi $\mathrm{AB}$. Brain gains: a literature review of medical missions to low and middle-income countries. BMC Health Serv Res. 2012;12(1):134. http://dx.doi.org/10.1186/1472-6963-12-134

11. Provenzano AM, Graber LK, Elansary M, Khoshnood K,Rastegar A, Barry M. Short-term global health research projects by US medical students: ethical challenges for partnerships. Am J Trop Med Hyg.
2010;83(2):211-4. http://dx.doi.org/10.4269/ajtmh.2010.09-0692

12. Roberts M. A piece of my mind. Duffle bag medicine. JAMA. 2006;295(13):1491-2. http://dx.doi.org/10.1001/jama.295.13.1491

13. Snyder J, Dharamsi S, Crooks VA. Fly-By medical care: conceptualizing the global and local social responsibilities of medical tourists and physician voluntourists. Globalization and Health. 2011;7:6. http://dx.doi.org/10.1186/1744-8603-7-6

14. Suchdev P, Ahrens K, Click E, Macklin L, Evangelista D, Graham E. A model for sustainable short-term international medical trips. Ambul Pediatr. 2007;7(4):317-20. http://dx.doi.org/10.1016/j.ambp.2007.04.003

15. Pinto AD, Upshur RE. Global health ethics for students. Dev World Bioeth. 2009;9(1):1-10. http://dx.doi.org/10.1111/j.1471-8847.2007.00209.x

16. Corbett S, Fikkert B. When helping hurts: how to alleviate poverty without hurting the poor... and yourself. Chicago: Moody Publishers; 2014.

17. Kittle N, McCarthy V. Teaching corner: raising the bar: ethical considerations of medical student preparation for short-term immersion experiences. J Bioeth Inq. 2015;12(1):79-84. http://dx.doi.org/10.1007/s11673-014-9601-9

18. Lahey T. Perspective: a proposed medical school curriculum to help students recognize and resolve ethical issues of global health outreach work. Acad Med. 2012;87(2):210-5. http://dx.doi.org/10.1097/ACM.0b013e31823f3fb1

19. Loh LC, Cherniak W, Dreifuss BA, Dacso, MM, Lin HC, Evert J. Short term global health experiences and local partnership models: a framework. Globalization and Health. 2015;11:50. http://dx.doi.org/10.1186/s12992-015-0135-7

20. Chad S, Brian T. Systems thinking in short-term health missions: a conceptual introduction and consideration of implications for practice. Christian J Glob Health. 2015;2(1):7-22. http://dx.doi.org/10.15566/cjgh.v2i1.50

21. Reynolds EC. Dealing with ethical challenges when leading student mission trips. J Am Dent Assoc. 2014;145(5):486-87. http://dx.doi.org/10.1016/S0002$\underline{8177(14) 60046-5}$

22. American Association of Medical Colleges [Internet]. Guidelines for premedical and medical students providing patient care during clinical experiences abroad, 2011.Available at: https://www.aamc.org/download/261648/data/coabull etin10.5.pdf

23. Wear D. Insurgent multiculturalism: rethinking how and why we teach culture in medical education. Acad Med. 2003;78(6):549-54.

24. Rosenman JR, Fischer PR, Arteaga GM, Hulvalkar M, Butteris SM, Pitt MB. Global health simulation during 
residency. Global Pediatr Health. 2016 Aug 22.

http:dx.doi.org/10.1177/2333794x1666354525

25. Butteris SM, Gladding SP, Eppich W, Hagen SA, Pitt MB, SUGAR Investigators. Simulation Use for Global Away Rotations (SUGAR): preparing residents for emotional challenges abroad - a multicenter study. Acad Pediatr. 2014;14(5):533-41. http://dx.doi.org/10.1016/j.acap.2014.05.00426

26. Wilkinson D, Symon B. Medical students, their electives, and HIV — Unprepared, ill advised, and at risk. Brit Med J. 1999;318(7177):139-40.

http://dx.doi.org/10.1136/bmj.318.7177.139

27. Minnesota Uo. Global Ambassadors for Patient Safety, 2016.

28. Mohan S, Suzanne S, Davidson H. Human immunodeficiency virus postexposure prophylaxis for medical trainees on international rotations. J Trav Med. 2010;17(4): 264-8. http://dx.doi.org/10.1111/j.1708-8305.2010.00421.x

Peer Reviewed

Competing Interests: None declared.

Correspondence: Kristen L Sessions, Mayo Clinic, United States. sessions.kristen@mayo.edu

Cite this article as: Sessions KL, Phillips JD, Merry SP. Avoiding pitfalls in overseas medical educational experiences. Christian Journal for Global Health. Mar 2017; 4(1): 24-29.

(C) Sessions KL, Phillips JD, Merry SP This is an open-access article distributed under the terms of the Creative Commons Attribution License, which permits unrestricted use, distribution, and reproduction in any medium, provided the original author and source are properly cited. To view a copy of the license, visit https://creativecommons.org/licenses/by/4.0/

wWw.cjgh.org

Mar 2017. Christian Journal for Global Health, 4(1): 24-29. 